\title{
Cognitive function and living situation in COPD: is there a relationship with self-management and quality of life?
}

This article was published in the following Dove Press journal:

International Journal of COPD

10 September 2015

Number of times this article has been viewed

\author{
Megan M Dulohery' \\ Darrell R Schroeder ${ }^{2}$ \\ Roberto P Benzo' \\ 'Division of Pulmonary and Critical \\ Care Medicine, Mindful Breathing \\ Laboratory, ${ }^{2}$ Department of Health \\ Sciences Research, Mayo Clinic. \\ Rochester, MN, USA
}

Background: Cognitive impairment is increasingly being found to be a common comorbidity in chronic obstructive pulmonary disease (COPD). This study sought to understand the relationship of comprehensively measured cognitive function with COPD severity, quality of life, living situation, health care utilization, and self-management abilities.

Methods: Subjects with COPD were recruited from the outpatient pulmonary clinic. Cognitive function was assessed using the Montreal Cognitive Assessment (MOCA). Self-management abilities were measured using the Self Management Ability Score 30. Quality of life was measured using the Chronic Respiratory Disease Questionnaire. Pearson correlation was used to assess the bivariate association of the MOCA with other study measures. Multivariate analysis was completed to understand the interaction of the MOCA and living situation on COPD outcomes of hospitalization, quality of life, and self-management ability.

Results: This study included 100 participants of mean age $70 \pm 9.4$ years $(63 \%$ male, 37\% female) with COPD (mean $\mathrm{FEV}_{1}$ [forced expiratory volume in 1 second] percentage predicted $40.4 \pm 16.7$ ). Mean MOCA score was $23.8 \pm 3.9$ with $63 \%$ of patients having mild cognitive impairment. The MOCA was negatively correlated with age $(r=-0.28, P=0.005)$ and positively correlated with education $(r=+0.24, P=0.012)$. There was no significant correlation between cognitive function and exacerbations, emergency room (ER) visits, or hospitalizations. There was no association between the MOCA score and self-management abilities or quality of life. We tested the interaction of living situation and the MOCA with self-management abilities and found statistical significance $(P=0.017)$, indicating that individuals living alone with higher cognitive function report lower self-management abilities.

Conclusion: Cognitive impairment in COPD does not appear to be meaningfully associated with COPD severity, health outcomes, or self-management abilities. The routine screening for cognitive impairment due to a diagnosis of COPD may not be indicated. Living alone significantly affects the interaction between self-management abilities and cognitive function.

Keywords: COPD, cognitive impairment, self-management ability

\section{Introduction}

Cognitive impairment is increasingly being found to be a common comorbidity in chronic obstructive pulmonary disease (COPD). ${ }^{1-3}$ The Mayo Clinic Study of Aging has demonstrated that patients with COPD have an increased risk of mild cognitive impairment. ${ }^{3}$ The Cardiovascular Health Study found that patients with coexisting COPD and cognitive impairment have increased respiratory-related and all-cause hospitalization compared to those with COPD or cognitive impairment alone. ${ }^{4} \mathrm{~A}$ more recent study found that patients with a recent exacerbation of the disease had worse cognitive function compared to stable COPD or controls..$^{5}$ In fact, $57 \%$ of those
Correspondence: Roberto P Benzo Division of Pulmonary and Critical Care Medicine, Mindful Breathing Laboratory, Mayo Clinic, 200 First Street SW Rochester, MN 55905, USA

Tel + I 507774056 I

Fax +I 5072664372

Email benzo.roberto@mayo.edu 
with exacerbation were in the impaired range, with $20 \%$ considered to have a pathologic loss in processing speed. ${ }^{5} \mathrm{~A}$ number of the patients with mild-to-severe cognitive impairment were discharged home without the impairment being recognized, demonstrating that significant impairment can easily be missed by the medical community.

Self-management is increasingly considered a meaningful outcome in COPD. Efforts have been made to investigate patient self-management in COPD as early treatment of exacerbations has been found to improve time to recovery, quality of life, and reduced risk of hospitalization. ${ }^{6}$ A recent study testing a selfmanagement intervention in COPD reported that the participants who followed the self-management plan had a reduced risk of hospital readmission were younger and were less likely to live alone compared to those who did not follow the plan. ${ }^{7}$ This study suggests that not only is patient engagement with health care critical to make an impact on outcomes but also that age and living situation are important factors for that engagement. Any analysis of self-management may need to adjust for those important covariants. It is not clear if cognitive impairment could be a barrier to learning self-management as cognitive impairment is more common in the elderly and executive function deficits are commonly seen. ${ }^{1}$ The latter is a research question that we wanted to address.

This study sought to understand the relationship of comprehensively measured cognitive function with COPD severity, quality of life, living situation, health care utilization, and self-management abilities.

\section{Methods}

The study was conducted from August 18, 2013, through May 7, 2014. Subjects with COPD were recruited from the outpatient pulmonary clinic at the Mayo Clinic, Rochester, MN, USA. Eligibility criteria are: 1) diagnosis of COPD based on the Global Initiative for Chronic Obstructive Lung Disease (GOLD) 2011 guidelines $;{ }^{8}$ 2) age $\geq 18$ years; 3 ) able to complete questionnaires in English; and 4) pulmonary function testing within the last 12 months. Subjects were excluded if they were: 1) unable to provide informed consent or 2) could not complete the cognitive function assessment due to vision loss or inability to speak. Participants completed the cognitive function assessment without assistance but were allowed to be assisted by family or friends to complete the additional questionnaires.

\section{Ethics}

This study was approved by the Mayo Institutional Review Board Minimal Risk Committee IRB 12-006156, and written informed consent was obtained from all patients. This study was conducted in accordance with the amended Declaration of Helsinki.

\section{Assessments}

\section{Cognitive function assessment}

The Montreal Cognitive Assessment (MOCA) is a screening tool for cognitive impairment. It is a 30-point test that assesses short-term memory, visuospatial ability, executive function, verbal abstraction, phonemic fluency, attention, concentration, and language. ${ }^{9,10}$ The MOCA has a high internal consistency with a Cronbach's $\alpha$ of $0.83 .{ }^{9}$ The MOCA has a sensitivity of $90 \%$ and specificity of $100 \%$ for identifying mild cognitive impairment when a cutoff of $<26$ is used. ${ }^{9}$ This test has a high retest reliability with a mean change of $0.9 \pm 2.5$ points and a retest correlation of $0.92, P<0.001$. $^{9}$

\section{Self-management ability}

The Self-Management Ability Score 30 (SMAS-30) is a 30-item questionnaire validated in COPD and other chronic diseases that measures self-management ability. The score assesses the six core self-management abilities: taking initiatives, investment behavior, variety, multifunctionality, self-efficacy, and positive frame of mind. ${ }^{11}$ This scale has a high internal consistency with a Cronbach's $\alpha$ of $0.91 .{ }^{12}$ The intraclass correlation is 0.76 , indicating good reproducibility. ${ }^{12}$ Higher scores indicate higher selfmanagement abilities. ${ }^{13}$

\section{General survey}

The general survey contains four items addressing the following: 1) smoking status; 2) COPD exacerbations; 3) hospitalizations for respiratory and nonrespiratory causes; and 4) ER/urgent care visits for respiratory and nonrespiratory causes. Exacerbations, hospitalizations, and emergency room (ER)/urgent care visits were confirmed when possible in the Mayo Medical Record for local patients. Data regarding living situation, comorbidities, and activities of daily living were also obtained from the medical record as they are part of the current visit questionnaire used for all patients at the Mayo Clinic.

\section{Pulmonary function testing}

All patients included in the study had pulmonary function testing completed within the last 12 months in the outpatient pulmonary function lab. The severity of the airflow limitation was classified based on the GOLD criteria. ${ }^{14}$ 


\section{Gait speed}

The $4 \mathrm{~m}$ gait speed was assessed as a measure of exercise capacity and frailty. ${ }^{15}$ A gait speed $<0.8 \mathrm{~m} / \mathrm{s}$ has been associated with frailty. ${ }^{16}$

The $4 \mathrm{~m}$ gait speed was measured at the patient's usual pace in an unobstructed clinic hallway. Each walk was performed with a $2 \mathrm{~m}$ rolling start where the participants are already walking as they enter the measuring area. Canes, walkers, and supplemental oxygen were used if the patient normally used the equipment in daily activity. Two cones were placed $8 \mathrm{~m}$ apart, and then an automated timing system was set up $2 \mathrm{~m}$ after the first cone and $2 \mathrm{~m}$ before the second cone. We used the Dual Beam Wireless Infrared Timing System (TracTronix, Lenexa, KS, USA).

\section{Depression screen}

The Patient Health Questionnaire-2 is a validated two-item depression-screening questionnaire. ${ }^{17}$ The test has an internal consistency of $\alpha=0.83$ as assessed by Cronbach's $\alpha .{ }^{17}$ A Patient Health Questionnaire-2 score of $\geq 3$ has a sensitivity of $87 \%$ and a specificity of $78 \%$ for major depressive disorder and a sensitivity of $79 \%$ and a specificity of $86 \%$ for any depressive disorder. ${ }^{17}$

\section{Quality of life}

Chronic Respiratory Disease Questionnaire (CRQ) selfadministered with the standardized dyspnea domain is a valid, reliable, and responsive instrument for the assessment of short-term quality of life change in patients with COPD exacerbations. ${ }^{18}$ Higher scores imply better self-reported disease-specific quality of life. ${ }^{18}$ The fatigue, emotion, and mastery domains have high internal reliability $(\alpha=0.71-0.88)$ as well as a high test-retest reliability $(P>0.90) .{ }^{19}$ The dyspnea domain has a lower internal reliability $(\alpha=0.53)$ and a test-retest reliability of $P=0.73 .{ }^{19}$

\section{Dyspnea}

The Modified Medical Research Council Dyspnea scale is a five-item tool used to assess dyspnea in patients with COPD.$^{20}$ Interobserver agreement is high for this scale with a weighted kappa of $0.92 .^{21}$

\section{Disease severity}

Disease severity was assessed using the age-dyspneaobstruction (ADO) index and the GOLD severity classification. The ADO index is a recognized marker of disease severity in COPD as a predictor of the 3-year mortality risk. ${ }^{22}$ The scoring range of the ADO was 0-14 with 14 being the highest risk. ${ }^{22}$ The GOLD severity classification determines disease severity based on the degree of obstruction. ${ }^{8}$

\section{Statistical analysis}

Data are summarized using mean \pm standard deviation for continuous variables and number $(\%)$ for nominal variables. The objective of the current study was to assess the relationship of cognitive function (MOCA) with COPD severity, outcomes, quality of life, and self-management abilities. The Pearson product-moment correlation was used to assess the bivariate association of MOCA with other study measures. In order to test the hypothesis that the association of cognitive function with COPD outcomes (exacerbations, ER visits, hospitalizations), quality of life (CRQ total score), or self-management abilities (SMAS total score) differed for participants who were living alone versus those who were not, a series of multivariable analyses were performed. For these analyses, MOCA score and living situation were the explanatory variables of interest. Age and [forced expiratory volume in 1 second]) were included as covariates. The MOCA-by-living situation interaction was included in the model to test whether the association of the MOCA with the given outcome was dependent on living status. If the MOCA-by-living situation interaction was found to be statistically significant, supplemental analyses were performed to assess the association of the MOCA with the given outcome separately for those who lived alone versus those who did not. In all cases, two-tailed tests were used with $P$-values $\leq 0.05$ used to denote statistical significance.

\section{Results}

This study included 100 participants (63\% male, 37\% female) with COPD based on GOLD criteria (2\% I-mild, 27\% IImoderate, 41\% III-severe, and 29\% IV-very severe). The mean \pm standard deviation cognitive function score, as assessed by the MOCA, was $23.8 \pm 3.9$, with $63 \%$ of patients scoring below the cutoff of 26 , which previous studies have shown to be consistent with mild cognitive impairment. ${ }^{9}$ A cutoff of 22 has been found to be more specific for mild cognitive impairment, and $24 \%$ of the patients in this study had MOCA scores $<22$. Two patients were diagnosed with dementia after enrollment. These patients had not been hospitalized for COPD in the past year.

Additional baseline characteristics of the study participants are tabulated in Table 1 along with the bivariate correlation of each characteristic with MOCA score. The mean SMAS total score was $64.1 \pm 10.9$ on a scale of $0-100$ with higher scores being associated with higher self-management ability. The mean CRQ score was $4.7 \pm 1.2$ on a seven-point 
Table I Patient characteristics

\begin{tabular}{|c|c|c|c|c|}
\hline \multirow[t]{2}{*}{ Characteristics } & \multirow[t]{2}{*}{ Number } & \multirow[t]{2}{*}{ Mean \pm SD } & \multicolumn{2}{|c|}{ Correlation with MOCA } \\
\hline & & & $r^{*}$ & $P$-value \\
\hline Age, years & 100 & $70.0 \pm 9.4$ & -0.28 & 0.005 \\
\hline Male & 100 & $63(63 \%)$ & $\#$ & 0.112 \\
\hline Lives alone & 100 & $24(24 \%)$ & $\#$ & 0.752 \\
\hline Education, years & 100 & $13.3 \pm 2.3$ & +0.24 & 0.012 \\
\hline MOCA & 100 & $23.8 \pm 3.9$ & - & - \\
\hline $\mathrm{FEV}_{\curlywedge}, \%$ predicted & 99 & $40.4 \pm 16.7$ & +0.06 & 0.584 \\
\hline Gait speed, $\mathrm{m} / \mathrm{s}$ & 70 & $1.1 \pm 0.2$ & +0.32 & 0.008 \\
\hline mMRC dyspnea scale & 100 & $2.2 \pm 1.2$ & -0.05 & 0.605 \\
\hline ADO index & 99 & $8.8 \pm 2.4$ & -0.27 & 0.005 \\
\hline Depression screening (PHQ-2) & 100 & $1.3 \pm 1.7$ & +0.08 & 0.428 \\
\hline CRQ & 87 & & & \\
\hline Dyspnea & & $5.1 \pm 1.5$ & +0.08 & 0.440 \\
\hline Fatigue & & $3.9 \pm 1.4$ & -0.05 & 0.668 \\
\hline Emotion & & $4.8 \pm 1.2$ & +0.16 & 0.135 \\
\hline Mastery & & $4.9 \pm 1.5$ & -0.04 & 0.714 \\
\hline CRQ - total score & & $4.7 \pm 1.2$ & +0.04 & 0.693 \\
\hline SMAS-30 & 99 & & & \\
\hline Taking initiatives & & $65.9 \pm 15.5$ & -0.08 & 0.429 \\
\hline Investment behavior & & $59.5 \pm 15.0$ & -0.08 & 0.438 \\
\hline Variety & & $41.6 \pm 14.6$ & +0.00 & 0.998 \\
\hline Multifunctionality & & $69.0 \pm 11.8$ & +0.02 & 0.845 \\
\hline Self-efficacy & & $84.3 \pm 13.4$ & -0.00 & 0.981 \\
\hline Positive frame of mind & & $64.2 \pm 17.7$ & +0.06 & 0.551 \\
\hline SMAS - total score & & $64.1 \pm 10.9$ & -0.02 & 0.862 \\
\hline Exacerbations in last year & 100 & & +0.04 & 0.717 \\
\hline 0 & & 44 & & \\
\hline I & & 21 & & \\
\hline 2 & & 15 & & \\
\hline 3 or more & & 20 & & \\
\hline ER visits for breathing problems in last year & 100 & & +0.06 & 0.564 \\
\hline 0 & & 62 & & \\
\hline I & & 19 & & \\
\hline 2 & & 11 & & \\
\hline 3 or more & & 8 & & \\
\hline Hospitalization for breathing problems in last year & 100 & & -0.04 & 0.661 \\
\hline 0 & & 72 & & \\
\hline I & & 18 & & \\
\hline 2 & & 11 & & \\
\hline 3 or more & & 3 & & \\
\hline
\end{tabular}

Notes: *Pearson product-moment correlation coefficient; " the mean \pm SD MOCA score was $23.3 \pm 4.2$ for males and $24.6 \pm 3.4$ for females ( $t$-test, $P=0.1$ I 2 ). For patients who lived alone, the mean \pm SD MOCA score was 24.2 \pm 3.8 ; for those who did not live alone, the mean \pm SD MOCA score was $23.9 \pm 3.9$ ( $t$-test, $P=0.752$ ).

Abbreviations: SD, standard deviation; MOCA, Montreal Cognitive Assessment; mMRC, modified Medical Research Council; ADO, age-dyspnea-obstruction; PHQ-2, two-item depression-screening questionnaire; CRQ, Chronic Respiratory Disease Questionnaire; SMAS-30, Self-Management Ability Score 30; ER, emergency room; FEV, forced expiratory volume in I second.

scale with higher scores indicating better health-related quality of life. MOCA score was found to be negatively correlated with age $(r=-0.28, P=0.005)$ and positively correlated with education $(r=+0.24, P=0.012)$. MOCA score was also found to be positively correlated with gait speed $(r=+0.32, P=0.008)$ and negatively correlated with the ADO index $(r=-0.27, P=0.005)$. From a multivariable analysis adjusting for age, there was still evidence suggesting that gait speed was increased with higher MOCA scores (slope estimate $=+0.02 \mathrm{~m} / \mathrm{s}$ change in gait speed per one unit increase in MOCA, $P=0.034$ ). After adjusting for age, the association between the MOCA score and the ADO index was no longer statistically significant $(P=0.175)$.

There was no significant bivariate correlation between cognitive function and the number of exacerbations, ER visits, or hospitalizations in the previous year. There was also no significant correlation between the MOCA score and the total SMAS or any of the self-management domains as 
seen in Table 1. Similarly, there was no significant bivariate correlation between the MOCA score and quality of life as measured by the CRQ.

A series of multivariable analyses were performed to assess whether the relationship of cognitive function with COPD outcomes and self-management was dependent on living situation. From these analyses, there was no significant evidence of a two-way interaction between the MOCA score and living situation for the number of exacerbations in the previous year $(P=0.604)$, the number of ER visits for breathing problems in the previous year $(P=0.784)$, or the number of hospitalizations for breathing problems in the previous year $(P=0.144)$. However, for SMAS total score and CRQ total score, the MOCA-by-living status interaction was found to be statistically significant $(P=0.017$ and $P=0.040$, respectively) indicating that the association of cognitive function with self-management and quality of life depends upon whether or not the individual is living alone. Supplemental analyses assessing the association of cognitive function with SMAS and CRQ scales were performed separately for those who were living alone and not living alone. Among those who lived alone, higher MOCA was associated with higher quality of life (CRQ) and lower self-management (SMAS), Table 2. Among those who did not live alone, there was no evidence that cognitive function was associated with quality of life or self-management.

\section{Discussion}

This study evaluated cognitive function in COPD patients in the outpatient clinic, and we found no association between cognitive function and important COPD outcomes: quality of life and health care utilization. There has been ongoing interest in the study of cognitive impairment as it has been found to be prevalent in the COPD population. We had postulated that the prevalence of cognitive impairment in this group might explain the difficulty that some COPD patients have managing their disease. We found no univariate association with cognitive function and health care utilization, quality of life, or self-management abilities. The strongest associations with cognitive function seem to be age and educational level, which are known factors that impact cognitive function. There was a mild correlation with the ADO index, a predictor of 3-year mortality risk. However, the latter is likely secondary to the age component of the score rather than a true association for severity of disease. Current literature has been very limited in the exploration of barriers to self-management and the impact of cognitive function. This study suggests that, although many COPD patients have some degree of cognitive impairment, it is not severe enough to impact health care utilization, self-management abilities, or quality of life in most patients.

Our study sought to further explore the association of selfmanagement abilities with cognitive function to determine the relationship in a subset of patients. While we found no association between self-management abilities and cognitive function using univariant analysis, we did find an association when the analysis was adjusted by living situation. The Glasgow Supported Self-management trial has previously demonstrated that patients who live alone are less likely to

Table 2 Association of MOCA score with CRQ and SMAS scales according to living situation*

\begin{tabular}{|c|c|c|c|c|c|c|}
\hline & \multicolumn{3}{|c|}{ Does not live alone } & \multicolumn{3}{|c|}{ Lives alone } \\
\hline & Estimate & SE & $P$-value & Estimate & SE & $P$-value \\
\hline \multicolumn{7}{|l|}{ CRQ } \\
\hline CRQ - total & -0.02 & $(0.04)$ & 0.682 & +0.15 & $(0.07)$ & 0.040 \\
\hline Dyspnea & -0.01 & $(0.04)$ & 0.867 & +0.25 & $(0.07)$ & 0.002 \\
\hline Fatigue & -0.06 & $(0.04)$ & 0.216 & +0.06 & $(0.09)$ & 0.470 \\
\hline Emotion & +0.03 & $(0.04)$ & 0.460 & +0.17 & $(0.08)$ & 0.053 \\
\hline Mastery & -0.03 & $(0.05)$ & 0.548 & +0.14 & $(0.08)$ & 0.095 \\
\hline \multicolumn{7}{|l|}{ SMAS } \\
\hline SMAS - total & +0.40 & $(0.32)$ & 0.218 & -1.67 & $(0.75)$ & 0.038 \\
\hline Taking initiatives & -0.02 & $(0.46)$ & 0.971 & -1.17 & $(\mathrm{l} .08)$ & 0.292 \\
\hline Investment behavior & +0.39 & $(0.47)$ & 0.412 & -2.11 & $(0.79)$ & 0.016 \\
\hline Variety & +0.96 & $(0.44)$ & 0.031 & -2.21 & $(0.74)$ & 0.008 \\
\hline Multifunctionality & +0.36 & $(0.37)$ & 0.335 & -1.55 & $(0.80)$ & 0.068 \\
\hline Self-efficacy & +0.27 & $(0.42)$ & 0.531 & -1.37 & $(0.83)$ & 0.116 \\
\hline Positive frame of mind & +0.42 & $(0.56)$ & 0.448 & -1.58 & $(\mathrm{I} .08)$ & 0.163 \\
\hline
\end{tabular}

Notes: *Analyses were performed separately for those who lived alone and those who did not live alone by using multiple linear regression to assess the association of the MOCA score with the given scale score after adjusting for patient age and percentage of predicted $\mathrm{FEV}_{1}$. Findings are summarized by presenting the estimated regression coefficient for the MOCA score along with the corresponding standard error (SE) and $P$-value.

Abbreviations: MOCA, Montreal Cognitive Assessment; CRQ, Chronic Respiratory Disease Questionnaire; SMAS, Self-Management Ability Score; FEV, forced expiratory volume in I second. 
follow a self-management plan. ${ }^{7}$ Another qualitative study found that COPD patients spontaneously developed selfcare activities but experienced difficulties with self-care if family was not supportive. ${ }^{23}$ In patients who were living alone, higher cognitive function was associated with lower patient-reported self-management abilities. In patients living with a spouse, domestic partner, or family, higher cognitive function was associated with higher patient-reported selfmanagement abilities. The reason for these differences is not clear but living situation appears to be a strong driver for the patient's perception of their ability to manage his/ her disease. We speculate that the patients living alone with higher cognitive function may be more aware of their limitations due to COPD in the context of no household help and are more frustrated or depressed as a result. On the contrary, patients with better cognitive function have better self-management abilities. Our findings are very novel and ignite the need for further research regarding social support for this population.

This study did not find a relationship between health care utilization and either cognitive function or self-management abilities. Our study included patients with all severities of COPD with similar educational levels; hence, we feel this population is representative of the general COPD population being seen in the outpatient pulmonary clinic. Several patients had recurrent exacerbations and/or hospitalizations. In our previous work using the digit symbol substitution test to evaluate cognitive function, we found that only patients with two or more hospitalizations in the past year had low digit symbol substitution test scores, indicating lower cognitive function. This study suggested that only COPD patients with overall poor health status had significant cognitive impairment. Our current study continues to support the finding that cognitive impairment in COPD patients is not severe enough to impact health outcomes in the majority of COPD patients. Mild cognitive impairment is a risk factor for progression to dementia but the US Preventive Services Task Force is not currently recommending screening for cognitive impairment. ${ }^{24}$ Based on our findings, we cannot recommend cognitive function screening in the outpatient pulmonary clinic for COPD patients.

\section{Limitations}

Our study does have limitations. As this is a cross-sectional study, we were unable to test if the deterioration in cognitive abilities has an impact in significant outcomes or if there is a phenotype of COPD that may predict a rapid decline of cognitive abilities. Sample size may be a limitation in the study. While we believe we did not miss any large or clinically meaningful association, a larger study may be able to pick up smaller associations.

\section{Conclusion}

Cognitive impairment in COPD does not appear to be independently associated with COPD severity, health outcomes, or self-management abilities. The routine screening for $\operatorname{cog}$ nitive impairment due to a diagnosis of COPD may not be indicated. Living alone significantly affects the interaction between self-management abilities and cognitive function.

\section{Acknowledgments}

We would like to thank Johanna Hoult and the Mindful Breathing Lab at the Mayo Clinic, Rochester for assistance with logistic planning of the study. We will like to thank the Mayo Clinic Robert D and Patricia E Kern Center for the Science of Health Care Delivery through Dr Dulohery's participation in the Health Care Delivery Scholars Program.

\section{Funding}

This publication was supported by Grant NIH - NHLBI 5R01HL094680-05 (PI Roberto Benzo) and by CTSA Grant Number UL1 TR000135 from the National Center for Advancing Translational Sciences (NCATS), a component of the National Institutes of Health (NIH). Its contents are solely the responsibility of the authors and do not necessarily represent the official view of NIH. This research was made possible by support from the Mayo Clinic Robert D and Patricia E Kern Center for the Science of Health Care Delivery through Dr Dulohery's participation in the Health Care Delivery Scholars Program.

\section{Author contributions}

Dr Dulohery contributed to study design, data collection, data analysis, and writing of the manuscript. Mr Schroeder contributed to the data analysis and writing of the manuscript. Dr Benzo (guarantor) contributed to the design of the study, data collection, data analysis, and writing of the manuscript. Dr Benzo takes responsibility for the content of the manuscript, including the data and analysis. All authors contributed toward data analysis, drafting and critically revising the paper and agree to be accountable for all aspects of the work.

\section{Disclosure}

The authors report no conflicts of interest in this work. 


\section{References}

1. Dodd JW, Getov SV, Jones PW. Cognitive function in COPD. Eur Respir J. 2010;35:913-922.

2. Schou L, Østergaard B, Rasmussen LS, Rydahl-Hansen S, Phanareth K. Cognitive dysfunction in patients with chronic obstructive pulmonary disease - a systematic review. Respir Med. 2012;106: 1071-1081.

3. Singh B, Parsaik AK, Mielke MM, et al. Chronic obstructive pulmonary disease and association with mild cognitive impairment: the Mayo Clinic Study of Aging. Mayo Clin Proc. 2013;88:1222-1230.

4. Chang SS, Chen S, McAvay GJ, Tinetti ME. Effect of coexisting chronic obstructive pulmonary disease and cognitive impairment on health outcomes in older adults. J Am Geriatr Soc. 2012;60:1839-1846.

5. Dodd JW, Charlton RA, van den Broek MD, Jones PW. Cognitive dysfunction in patients hospitalized with acute exacerbation of Chronic Obstructive Pulmonary Disease (COPD). Chest. 2013;144(1):119-127.

6. Wilkinson TM, Donaldson GC, Hurst JR, Seemungal TA, Wedzicha JA. Early therapy improves outcomes of exacerbations of chronic obstructive pulmonary disease. Am J Respir Crit Care Med. 2004;169: 1298-1303.

7. Bucknall CE, Miller G, Lloyd SM, et al. Glasgow supported selfmanagement trial (GSuST) for patients with moderate to severe COPD: randomised controlled trial. BMJ. 2012;344:e1060.

8. Vestbo J, Hurd SS, Rodriguez-Roisin R. The 2011 revision of the global strategy for the diagnosis, management and prevention of COPD (GOLD) - why and what? Clin Respir J. 2012;6:208-214.

9. Nasreddine ZS, Phillips NA, Bédirian V, et al. The Montreal Cognitive Assessment, MoCA: a brief screening tool for mild cognitive impairment. J Am Geriatr Soc. 2005;53:695-699.

10. Villeneuve S, Pepin V, Rahayel S, et al. Mild cognitive impairment in moderate to severe COPD: a preliminary study. Chest. 2012;142:1516-1523.

11. Cramm JM, Strating MM, de Vreede PL, Steverink N, Nieboer AP. Validation of the self-management ability scale (SMAS) and development and validation of a shorter scale (SMAS-S) among older patients shortly after hospitalisation. Health Qual Life Outcomes. 2012;10:9.

12. Schuurmans H, Steverink N, Frieswijk N, Buunk BP, Slaets JP, Lindenberg S. How to measure self-management abilities in older people by self-report. The development of the SMAS-30. Qual Life Res. 2005;14:2215-2228.
13. Cramm JM, Nieboer AP. Self-management abilities, physical health and depressive symptoms among patients with cardiovascular diseases, chronic obstructive pulmonary disease, and diabetes. Patient Educ Couns. 2012;87:411-415.

14. Vestbo J, Hurd SS, Agustí AG, et al. Global strategy for the diagnosis, management, and prevention of chronic obstructive pulmonary disease: GOLD executive summary. Am J Respir Crit Care Med. 2013; 187:347-365.

15. DePew ZS, Karpman C, Novotny PJ, Benzo RP. Correlations between gait speed, six-minute walk, physical activity, and self-efficacy in severe chronic lung disease. Respir Care. 2013;58(12):2113-2119.

16. Abellan van Kan G, Rolland Y, Andrieu S, et al. Gait speed at usual pace as a predictor of adverse outcomes in community-dwelling older people an International Academy on Nutrition and Aging (IANA) Task Force. J Nutr Health Aging. 2009;13:881-889.

17. Lowe B, Kroenke K, Grafe K. Detecting and monitoring depression with a two-item questionnaire (PHQ-2). J Psychosom Res. 2005;58:163-171.

18. Aaron SD, Vandemheen KL, Clinch JJ, et al. Measurement of shortterm changes in dyspnea and disease-specific quality of life following an acute COPD exacerbation. Chest. 2002;121:688-696.

19. Wijkstra PJ, TenVergert EM, Van Altena R, et al. Reliability and validity of the chronic respiratory questionnaire (CRQ). Thorax. 1994;49:465-467.

20. Bestall JC, Paul EA, Garrod R, Garnham R, Jones PW, Wedzicha JA. Usefulness of the Medical Research Council (MRC) dyspnoea scale as a measure of disability in patients with chronic obstructive pulmonary disease. Thorax. 1999;54:581-586.

21. Mahler DA, Wells CK. Evaluation of clinical methods for rating dyspnea. Chest. 1988;93:580-586.

22. Puhan MA, Hansel NN, Sobradillo P, et al; International COPD Cohorts Collaboration Working Group. Large-scale international validation of the ADO index in subjects with COPD: an individual subject data analysis of 10 cohorts. BMJ Open. 2012;2(6).

23. Apps LD, Harrison SL, Williams JE, et al. How do informal self-care strategies evolve among patients with chronic obstructive pulmonary disease managed in primary care? A qualitative study. Int J Chron Obstruct Pulmon Dis. 2014;9:257-263.

24. Lin JS, O'Connor E, Rossom RC, Perdue LA, Eckstrom E. Screening for cognitive impairment in older adults: a systematic review for the U.S. Preventive Services Task Force. Ann Intern Med. 2013;159:601-612.
International Journal of COPD

\section{Publish your work in this journal}

The International Journal of COPD is an international, peer-reviewed journal of therapeutics and pharmacology focusing on concise rapid reporting of clinical studies and reviews in COPD. Special focus is given to the pathophysiological processes underlying the disease, intervention programs, patient focused education, and self management protocols.

\section{Dovepress}

This journal is indexed on PubMed Central, MedLine and CAS. The manuscript management system is completely online and includes a very quick and fair peer-review system, which is all easy to use. Visit http://www.dovepress.com/testimonials.php to read real quotes from published authors. 